\title{
RESEARCH
}

Open Access

\section{Tyrosinase@HKUST-1: a super stable biocatalyst efficient for catecholic product synthesis}

\author{
Xiao-Feng Lü ${ }^{1}$, Chao-Yun Feng ${ }^{1}$, Shuangfei Li ${ }^{2}$ Guo-Hao Liu² and Zhen Yang ${ }^{1 *}$ (i)
}

\begin{abstract}
Although metal-organic frameworks (MOFs) have been considered as promising matrices for enzyme immobilization, HKUST-1, constructed from copper acetate ( $\left.\mathrm{CuAc}_{2}\right)$ and benzene 1,3,5-tricarboxylate (BTC), has rarely been explored for this application. In this study, mushroom tyrosinase (EC 1.14.18.1) was immobilized in the form of tyrosinase@ HKUST-1 following a simple reaction procedure by mixing BTC with the enzyme prior to addition of $\mathrm{CuAC}_{2}$. The resultant biocatalyst was characterized in both structural features and catalytic properties. Upon incorporation into the HKUST-1 frameworks, the enzyme gained a prominent enhancement in stability against $\mathrm{pH}$, temperature and storage: When incubated at $50^{\circ} \mathrm{C}$ and pH 6.0, tyrosinase@HKUST-1 presented a half-life of $32.6 \mathrm{~h}$, which is 77 -fold and over tenfold higher than that of the free enzyme and its other immobilization forms, respectively; and the catalyst fully maintained its activity for at least 2 months when stored at $30^{\circ} \mathrm{C}$. The applicability of this new biocatalyst was demonstrated by employing it as catalyst for regioselective ortho-hydroxylation reactions to produce catecholic products with huge pharmacological effects, i.e., hydroxytyrosol and L-DOPA, with excellent yields and productivities. This study has thus offered a facile immobilization method to prepare a novel biocatalyst with super stability, and tyrosinase@ HKUST-1 so formed from crude mushroom extract provides an efficient catalyst which can be applied to the production of catecholic products with health benefits.
\end{abstract}

Keywords: Tyrosinase, HKUST-1, Metal-organic frameworks (MOFs), Catecholic products, o-Diphenols, Enzyme immobilization, Hydroxytyrosol, L-DOPA

\footnotetext{
${ }^{*}$ Correspondence: zyang@szu.edu.cn

${ }^{1}$ College of Life Sciences and Oceanography, Shenzhen Key Laboratory of Microbial Genetic Engineering, Shenzhen University, 1066 Xue Yuan Avenue, Shenzhen 518055, Guangdong, China

Full list of author information is available at the end of the article
}

\section{Springer Open}

(c) The Author(s) 2021. Open Access This article is licensed under a Creative Commons Attribution 4.0 International License, which permits use, sharing, adaptation, distribution and reproduction in any medium or format, as long as you give appropriate credit to the original author(s) and the source, provide a link to the Creative Commons licence, and indicate if changes were made. The images or other third party material in this article are included in the article's Creative Commons licence, unless indicated otherwise in a credit line to the material. If material is not included in the article's Creative Commons licence and your intended use is not permitted by statutory regulation or exceeds the permitted use, you will need to obtain permission directly from the copyright holder. To view a copy of this licence, visit http://creativecommons.org/licenses/by/4.0/. 


\section{Graphical Abstract}

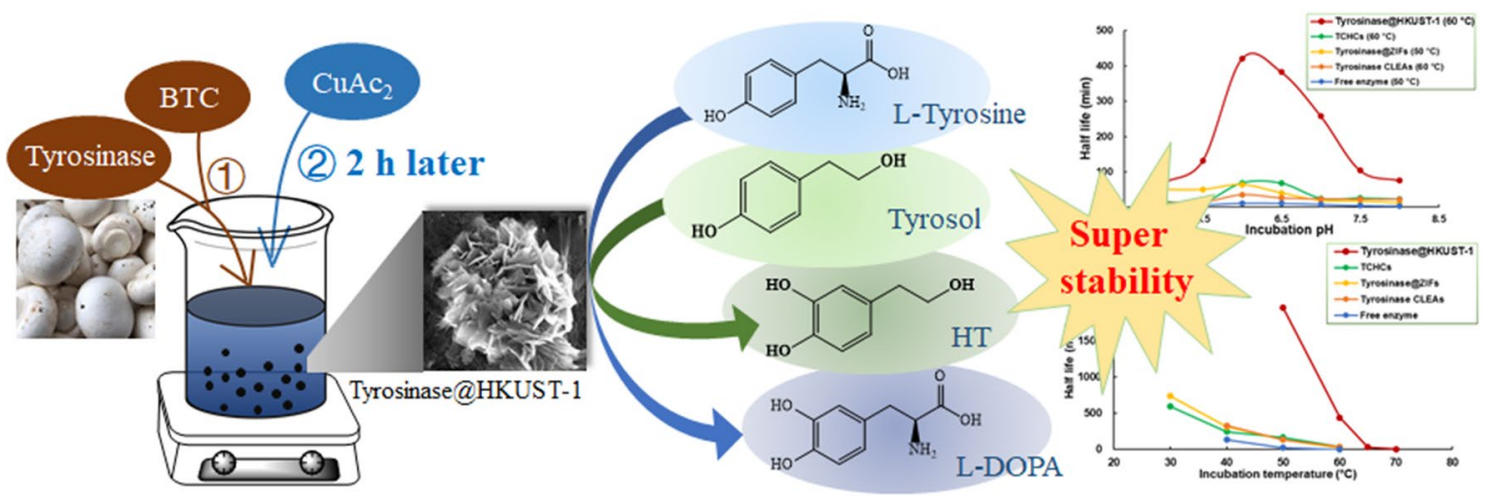

\section{Introduction}

As an emerging class of porous materials with a broad spectrum of applications which are ever-expanding, MOFs have gained increasing attention and interests (Yuan et al. 2018). In particular, MOFs have been recognized as novel matrices for efficient enzyme immobilization due to their fascinating structural and functional tunability, easy immobilization processing, and excellent catalytic performance presented by the enzyme-MOF hybrid composites (for reviews see (Vaidya et al. 2020; Liang et al. 2020)). Among them is HKUST-1, a highly porous metal coordination polymer with a molecular formula of $\left[\mathrm{Cu}_{3}(\mathrm{BTC})_{2}\left(\mathrm{H}_{2} \mathrm{O}\right)_{\mathrm{n}}\right]$ (BTC = benzene-1,3,5-tricarboxylate), which was first reported by Chui et al. (1999).

Although being one of the most extensively studied MOFs for applications such as gas separation and storage (Al-Janabi et al. 2015), HKUST-1 has rarely been explored for its potentials in enzyme immobilization. So far there are only two reports on this aspect. Nobakht et al. (2018) have tried to immobilize porcine pancreatic lipase (PPL) using HKUST-1 as the support, but the stability of the immobilized enzyme was only mildly improved as compared to that of the free enzyme. Zhang et al. (2020) have successfully prepared laccase@HKUST-1 biocomposites which are more active and stable than the free enzyme and have shown potential for degradation of bisphenol A.

This study was aimed to immobilize a new enzyme, mushroom tyrosinase (polyphenol oxidase, EC 1.14.18.1), as tyrosinase@HKUST-1 hybrid composites by following a simple reaction procedure we developed. Tyrosinase is a copper-containing oxidoreductase catalyzing the hydroxylation of monophenols to $o$-diphenols and their subsequent oxidation to $o$-quinones (Robb 1984). This enzyme has found promising potential in broad applications such as wastewater treatment (Atlow et al. 1984; $\mathrm{Xu}$ and Yang 2013), biosensor design (Nistor et al. 1999;
Wang et al. 2015; Lu et al. 2016), synthesis of pharmaceuticals and nutraceuticals (Pialis and Saville 1998; Cheng et al. 2018; Wei et al. 2020b), and prodrug activation for cancer therapy (Lian et al. 2018). Our previous work has demonstrated that this enzyme, when immobilized as cross-linked enzyme aggregates (CLEAs) (Xu et al. 2011), tyrosinase- $\mathrm{Cu}_{3}\left(\mathrm{PO}_{4}\right)_{2}$ hybrid composites (TCHCs) (Wei et al. 2020b), and tyrosinase@ZIF-8 (here ZIF=zeolitic imidazolate framework, a type of MOFs) (Wei et al. 2021), had its stability significantly enhanced as compared to the free enzyme.

The tyrosinase@HKUST-1 hybrid composites produced in this current study were found to present a super stability against $\mathrm{pH}$, temperature, storage and recycling. This new biocatalyst was also applied to the synthesis of catecholic products as a first attempt to explore its application potential.

\section{Materials and methods Materials}

L-Tyrosine was purchased from Sigma-Aldrich China Inc. Ammonium persulfate (APS), N,N,N,N'-tetramethylethylenediamine (TEMED) were purchased from Sangon Biotech (Shanghai) Co., Ltd. Acrylamide/bisacrylamide solution (29:1) was from Labgic Technology Co., Ltd. L-3,4-dihydroxyphenylalanine (L-DOPA), benzene 1,3,5-tricarboxylate (BTC), copper acetate $\left(\mathrm{CuAc}_{2}\right)$ monohydrate, tyrosol, hydroxytyrosol (HT), L-ascorbic acid, and all other chemicals were obtained from Shanghai Macklin Biochemical Co., Ltd. Crude tyrosinase solution was prepared from fresh mushrooms (Agaricus bisporus) as described in (Yang and Robb 1993).

\section{Preparation and characterization of tyrosinase@HKUST-1}

BTC $(9.70 \mathrm{~g})$ was added into $1 \mathrm{~L}$ crude enzyme solution, homogenized for $1 \mathrm{~min}$, followed by addition of $77 \mathrm{~mL}$ 
$\mathrm{NaAc}-\mathrm{HAc}$ buffer (200 mM, pH 7.0). The suspension was then mixed with a magnetic stirrer at $12{ }^{\circ} \mathrm{C}$ for $2 \mathrm{~h}$ before $77 \mathrm{~mL}$ of $90 \mathrm{mM} \mathrm{CuAc}_{2}$ solution in the acetate buffer was added. The mixture was then stirred at $12{ }^{\circ} \mathrm{C}$ for $8 \mathrm{~h}$. The resultant product was obtained after centrifugation at $10,000 \mathrm{rpm}$ for $10 \mathrm{~min}$, washing at least three times with acetate buffer, and vacuum drying at room temperature overnight. The produced tyrosinase@HKUST-1 was characterized, in comparison to the enzyme-free HKUST-1, by using X-ray diffraction (XRD, D8 ADVANCE, Bruker AXS, Germany), Fourier transform infrared spectroscopy (FT-IR, Nicolet 6700, Thermo Fisher Scientific, USA), scanning electron microscopy (SEM) and energydispersive X-ray diffraction spectroscopy (EDS) (APREO, Thermo Fisher, USA).

\section{Preparation of tyrosinase@HKUST-1@PAAm and tyrosinase@PAAm}

Tyrosinase@HKUST-1 was further entrapped into polyacrylamide (PAAm) gel by adding $120 \mathrm{mg}$ pulverized powders of the catalyst, $7.5 \mathrm{~mL}$ phosphate buffer ( $\mathrm{pH} 6.0$, $50 \mathrm{mM}$ ), $2.5 \mathrm{~mL} \mathrm{30 \%}$ acrylamide/bisacrylamide solution (29:1), $100 \mu \mathrm{L}$ 10\% APS solution and $10 \mu \mathrm{L}$ TEMED, in order, to a $15 \mathrm{~mL}$ test tube with a dimension of $1.5 \mathrm{~cm}$ (diameter) $\times 9 \mathrm{~cm}$ (length). After thorough mixing, the suspension was allowed to stay for polymerization at room temperature for $1 \mathrm{~h}$. The resultant cylindrical gel (tyrosinase@HKUST-1@PAAm) was then released from the test tube. After cleaning, it was carefully cut into 12 pieces of equal size, each with a weight of $\sim 0.75 \mathrm{~g}$, followed by being stored at $4 \mathrm{C}$ in phosphate buffer.

Tyrosinase@PAAm was prepared in the same way by mixing $6.0 \mathrm{~mL}$ crude enzyme solution, $1.5 \mathrm{~mL}$ phosphate buffer, $2.5 \mathrm{~mL} 30 \%$ acrylamide/bisacrylamide solution (29:1), $100 \mu \mathrm{L} 10 \%$ APS solution and $10 \mu \mathrm{L}$ TEMED.

\section{Activity and stability assays}

Activity: tyrosinase activity was assayed spectrophotometrically by following the oxidation of L-DOPA to dopachrome, which was reflected by an increase in the absorbance at $475 \mathrm{~nm}$ (Yang and Robb 1993). Typically, $5.0 \mathrm{mg}$ of tyrosinase@HKUST-1 was added to $10 \mathrm{~mL}$ of sodium phosphate buffer $(50 \mathrm{mM}, \mathrm{pH}$ 6.0) containing $0.8 \mathrm{mM} \mathrm{L}$-DOPA in a beaker, which was placed in a shaking incubator at $30{ }^{\circ} \mathrm{C}$ with agitation of $200 \mathrm{rpm}$. After reaction for $10 \mathrm{~min}$, a 2-mL sample was taken for absorbance reading at $475 \mathrm{~nm}$ as a measure of the initial reaction rate. All tests were carried out at least in triplicate with the coefficient of variation (\% CV) not greater than $5 \%$ and $10 \%$ for the free and immobilized enzyme, respectively.
Stability against $\mathrm{pH}$ and temperature: the residual activity of the enzyme was determined after incubation for a specified period at various $\mathrm{pH}$ 's $(\mathrm{pH} 5-8)$ and temperatures $\left(30-70{ }^{\circ} \mathrm{C}\right)$.

Recyclability: the immobilized enzyme was subjected to 10-min activity assay as described above. Then the catalyst was collected by centrifugation, followed by washing twice with phosphate buffer. Fresh substrate solution was then added for the next-round reaction.

Storage stability: the storage stability of the free and immobilized enzyme was examined by comparing the residual activity of the enzyme, free or immobilized, after being stored at $30^{\circ} \mathrm{C}$, in air or in phosphate buffer (50 mM, pH 6.0), for a certain period.

\section{Synthesis of hydroxytyrosol (HT) from tyrosol}

For a typical reaction, the substrate solution containing $2 \mathrm{mM}$ tyrosol and $55 \mathrm{mM} \mathrm{L}$-ascorbic acid in $10 \mathrm{~mL}$ phosphate buffer $(200 \mathrm{mM}, \mathrm{pH} 6.6)$ was placed in a shaking incubator with agitation of $250 \mathrm{rpm}$ at $30{ }^{\circ} \mathrm{C} .40 \mathrm{mg}$ of tyrosinase@HKUST-1 was added to start the reaction, and every 30 min samples were taken for HPLC analysis.

\section{Synthesis of L-DOPA from L-tyrosine}

A typical reaction was carried out by adding $50 \mathrm{mg}$ of tyrosinase@HKUST-1 to the substrate solution containing $2 \mathrm{mM}$ L-tyrosine and $30 \mathrm{mM}$ L-ascorbic acid in $10 \mathrm{~mL}$ of sodium phosphate buffer (100 mM, pH 7.0), with agitation of $250 \mathrm{rpm}$ at $30^{\circ} \mathrm{C}$. Every $30 \mathrm{~min}$ samples were taken for HPLC analysis.

\section{HPLC analysis}

HPLC analysis for the above two synthetic reactions was performed on a Shimadzu LC-16 HPLC system equipped with an SPD-16 UV/vis detector and a $150 \mathrm{~mm} \times 4.6 \mathrm{~mm}$, $5 \mu \mathrm{m}$ Inertsil ODS-SP column (GL Sciences Inc. Japan). For detection of tyrosol and hydroxytyrosol, a solvent mixture of $0.1 \%$ formic acid / $25 \%$ methanol was employed as the mobile phase with a flow rate of $1.0 \mathrm{ml} /$ $\mathrm{min}$, and the absorbance at $278 \mathrm{~nm}$ was followed within $10 \mathrm{~min}$. The HPLC analysis of L-tyrosine and L-DOPA was run with the mobile phase of $\mathrm{H}_{2} \mathrm{O} / \mathrm{CH}_{3} \mathrm{OH} / \mathrm{H}_{3} \mathrm{PO}_{4}$ (979.5:19.5:1 by volume, $\mathrm{pH}$ 2.0), as described in $\mathrm{Xu}$ et al. (2012).

\section{TLC detection}

Tyrosol and hydroxytyrosol were detected by running the thin-layer chromatography (TLC) plates with a solvent 
mixture of hexane/ethyl acetate/formic acid (60:40:2 by volume), followed by spraying with the vanillin reagent (2.5 g vanillin dissolved in an ethanol solution containing $10 \%$ (v/v) concentrated sulfuric acid).

\section{Results and discussion}

\section{Characterization of tyrosinase@HKUST-1}

Tyrosinase@HKUST-1 was prepared in aqueous solution under mild conditions by following the procedures described above in the Experimental Section. It has shown to be catalytically active. As displayed in Fig. 1a, its activity was correlated proportionally with the amount of the immobilized enzyme applied.

While the enzyme-free HKUST- 1 powders are blue (Fig. 1, b1), the tyrosinase@HKUST-1 composites are black (Fig. 1, b2). The EDS study (Fig. 1, c1, c2) provides evidence that the enzyme molecules have been incorporated into the HKUST-1 frameworks, as in the hybrid product there are new elements ( $\mathrm{N}$ and $\mathrm{S})$, which could come solely from protein molecules. The firm incorporation of the enzyme into the HKUST-1 frameworks was also ascertained by FT-IR analysis (Fig. 1d): The FT-IR spectrum of tyrosinase@HKUST-1 shows characteristic bands of the enzyme $\left(1648,1540,1250 \mathrm{~cm}^{-1}\right.$, corresponding to $\mathrm{C}=\mathrm{O}$ stretching vibration, $\mathrm{N}-\mathrm{H}$ bending vibration and $\mathrm{C}-\mathrm{H}$ stretching vibration of the protein's amide bond, respectively). Similar IR spectra were also observed for lipase@HKUST-1 (Nobakht et al. 2018) and laccase@HKUST-1 (Zhang et al. 2020).

The XRD patterns of both HKUST-1 and tyrosinase@ HKUST-1 we prepared showed no visible difference (Fig. 1e), both matching well with that of the simulated HKUST- 1 with characteristic peaks at $2 \theta \approx 6.5^{\circ}, 9.5^{\circ}$, $11.5^{\circ}$ and $13.4^{\circ}$ (Huo et al. 2013). This indicates that the structural integrity and crystallinity of the HKUST-1 crystals were highly preserved when the enzyme was encapsulated.

The morphologies of HKUST-1 (Fig. 1, f1) and tyrosinase@HKUST-1 (Fig. 1, f2) visualized by SEM look quite different: The enzyme-free HKUST-1 showed the bar-shaped structure, while tyrosinase@HKUST-1 formed microflowers with size distribution ranging between 5-20 $\mu \mathrm{m}$. Similar flower-like SEM images were also observed for laccase@HKUST-1 but with smaller sizes $(1-1.5 \mu \mathrm{m})$ (Zhang et al. 2020). As suggested by the authors (Zhang et al. 2020), the morphology of the enzyme@HKUST-1 composites different from that of the enzyme-free HKUST-1 crystals may be due to the aggregative growth kinetics mediated by the enzyme (and the substances contained in the crude enzyme solution in our case). Nevertheless, the microflower structure with a highly exposed surface area appearing in the hybrid biocatalyst is beneficial as it facilitates the substrate accessibility to the enzyme.

\section{Super stability presented by tyrosinase@HKUST-1}

Figure 2 presents a comparison of the stability of tyrosinase@HKUST-1 against both pH and temperature to that of the free enzyme and its three other immobilization forms prepared in our laboratory: tyrosinase CLEAs (Xu et al. 2011), TCHCs (Wei et al. 2020b), and tyrosinase@ZIF-8 (Wei et al. 2021).

As shown in Fig. 2a, encapsulation into HKUST-1 did not alter the enzyme's optimal $\mathrm{pH}$ for incubation (which is $\mathrm{pH}$ 6.0), but when incubated at $60{ }^{\circ} \mathrm{C}$ and $\mathrm{pH} \mathrm{6.0,} \mathrm{tyrosinase@}$ HKUST-1 achieved a long half-life of $7.0 \mathrm{~h}$, which was 5.1-, 5.6-, 10.9- and 37.9-fold higher than those obtained by TCHCs $\left(60{ }^{\circ} \mathrm{C}\right)$, tyrosinase@ZIF- $8\left(50{ }^{\circ} \mathrm{C}\right)$, tyrosinase CLEAs $\left(60^{\circ} \mathrm{C}\right)$ and the free enzyme $\left(50^{\circ} \mathrm{C}\right)$, respectively.

The thermostability of tyrosinase@HKUST-1 was also dramatically higher than that of the free enzyme and its other immobilization forms (Fig. 2b). Take the half-lives obtained at $50{ }^{\circ} \mathrm{C}$ as an example for comparison, tyrosinase@HKUST-1 exhibited a superb half-life of $32.6 \mathrm{~h}$, which was 11.8-, 14.5-, 14.7-, and 78.1-fold as high as those obtained by TCHCs, tyrosinase@ZIF-8, tyrosinase CLEAs and the free enzyme, respectively. In support of our findings, Zhang et al. (2020) have also observed a higher thermostability for laccase@HKUST-1 than that for laccase CLEAs. This may be explained by the fact that the HKUST-1 crystal matrices provide a more rigid structure and hence stronger protection to the enzyme than the cross-linked aggregates, thus preventing the enzyme molecules from conformational changes and in turn a loss in enzyme activity.

Tyrosinase@HKUST-1 also possessed an excellent storage stability. As shown in Fig. 3, upon incubation in phosphate buffer at $30^{\circ} \mathrm{C}$, the activity of tyrosinase@HKUST-1 remained fairly unchanged for at least 2 months (after that the tests were terminated), whereas the free enzyme completely lost its activity within 13 days. Interestingly, when incubated in air however, tyrosinase@HKUST-1 had its activity dropped to $35.5 \%$ of its original after 60 days of storage at the same temperature. A similar contrast was also observed when tyrosinase@HKUST-1 was further entrapped into polyacrylamide (PAAm) gel (i.e., tyrosinese@HKUST-1@PAAm), and the reason is uncertain yet which deserves a further investigation.

It is worth noting that the storage stability of our catalyst is much superior relative to that for lipase/HKUST-1 (Nobakht et al. 2018) and laccase/HKUST-1 (Zhang et al. 2020), the only two examples of enzyme immobilization with HKUST-1 as the support: While tyrosinase@ 

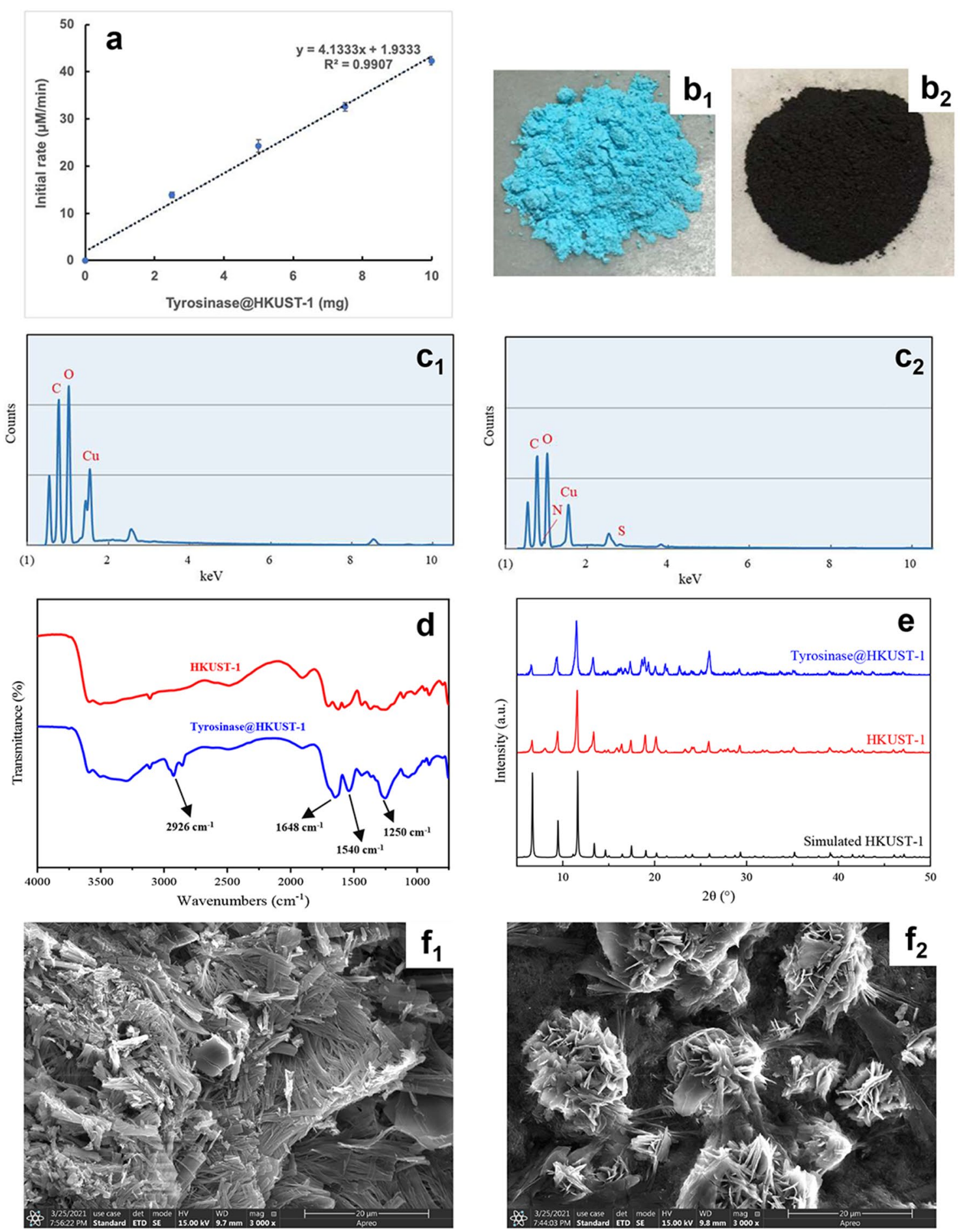

Fig. 1 Characterization of tyrosinase@HKUST-1: (a) activity assay; (b) photos of HKUST-1 (b1) and tyrosinase@HKUST-1 (b2); (c) EDS images of HKUST-1 (c1) and tyrosinase@HKUST-1 (c2); (d) FT-IR spectra of HKUST-1 and tyrosinase@HKUST-1; (e) XRD images of HKUST-1 and tyrosinase@ HKUST-1 as compared to that of the simulated HKUST-1; (f) SEM images of HKUST-1 (f1) and tyrosinase@HKUST-1 (f2) 

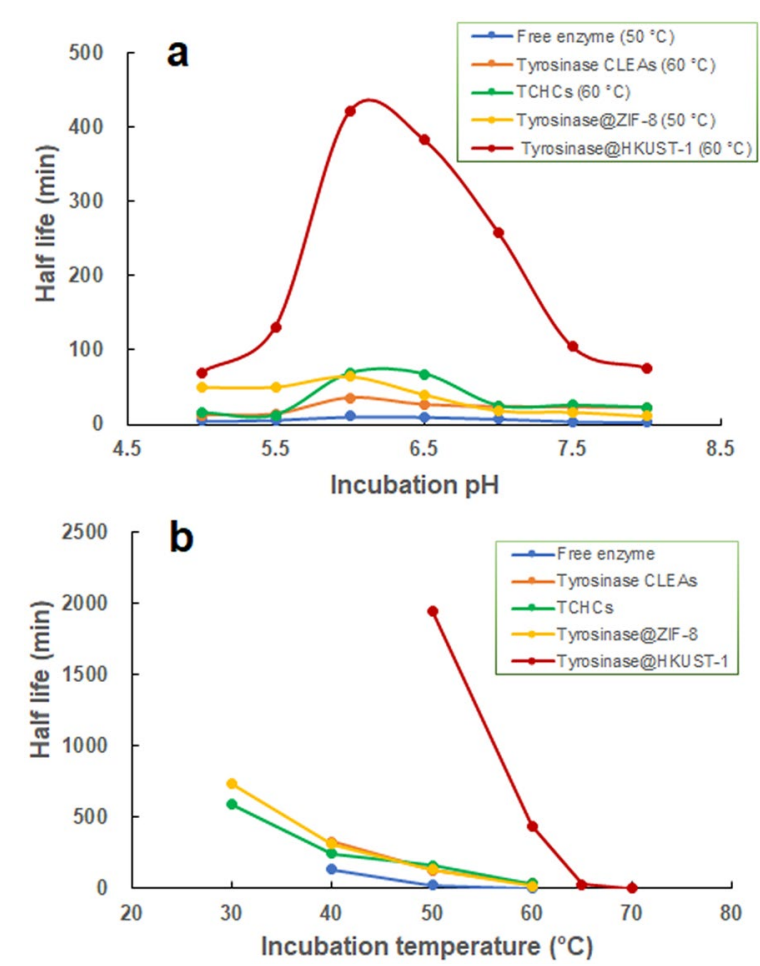

Fig. 2 A comparison of the stability of tyrosinase@HKUST-1 against $\mathrm{pH}(\mathbf{a})$ and temperature (b) with that of the free enzyme and its other three immobilization forms

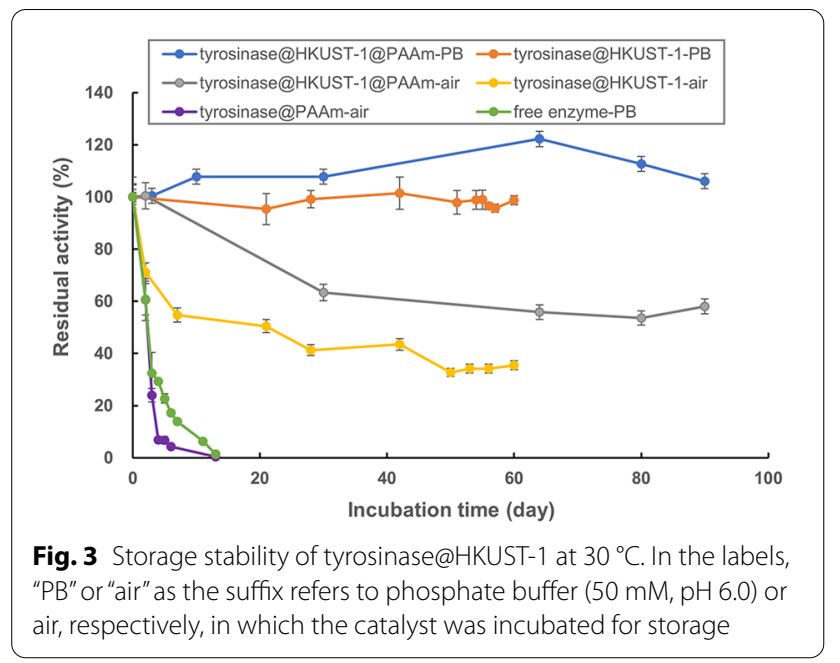

HKUST-1 maintained full activity after storage at $30{ }^{\circ} \mathrm{C}$ for more than 60 days, the latter two retained $80 \%$ and $70 \%$ of their original activities after storage at $4{ }^{\circ} \mathrm{C}$ for only 20 days and 30 days, respectively. Tyrosinase@ HKUST-1 is even more stable than the same enzyme immobilized as TCHCs (tyrosinase- $\mathrm{Cu}_{3}\left(\mathrm{PO}_{4}\right)_{2}$ hybrid composites), as the latter had its activity dropped to $77 \%$ of its original after 30 days of storage at $30{ }^{\circ} \mathrm{C}$ (Wei et al. 2020b). This may suggest that the HKUST-1 metalorganic coordination frameworks should possess a more stable structure than the inorganic $\mathrm{Cu}_{3}\left(\mathrm{PO}_{4}\right)_{2}$ crystals, thus providing stronger protection to the enzyme.

Although tyrosinase@HKUST-1 has shown to exhibit excellent catalytical performance, especially in terms of stability, it has to be admitted that this new biocatalyst was not well recyclable: almost half of its activity was lost after only 5 reaction cycles (Fig. 4), and the major reason is because the biocatalyst particles are too fine to be recovered for reuse. Our recent studies have proven that although the other three immobilization forms of mushroom tyrosinase (i.e., tyrosinase CLEAs, TCHCs and tyrosinase@ZIF-8) also did not behave well in recycling, a combination of them with other traditional immobilization methods such as entrapment into alginate gel offers a great solution for improving the catalyst's robustness and operability (Xu et al. 2012; Wei et al. 2020b, 2021). In this study, tyrosinase@HKUST-1 was endeavored to be entrapped into polyacrylamide gel. Indeed, the resultant tyrosinase@HKUST-1@PAAm was markedly more stabilized, fully maintaining its activity after storage for at least 3 months (Fig. 3) and after reaction for at least 10 cycles (Fig. 4). It is worth noting that here the stability enhancement was more attributed to the HKUST-1 frameworks rather than to the polyacrylamide gel. This is well illustrated when comparing the storage stability (Fig. 3) and recyclability (Fig. 4) of tyrosinase@PAAm to those of both tyrosinase@HKUST-1 and tyrosinase@HKUST-1@PAAm.

\section{A discussion about the preparation and its role in the stability of the so-formed catalyst}

In our opinion, the super stability presented by our tyrosinase@HKUST-1 relative to that of the other two enzymes both immobilized on HKUST-1, i.e., lipase@ HKUST-1 (Nobakht et al. 2018) and laccase@HKUST-1 (Zhang et al. 2020), is very much attributed to the different procedures used for their preparations.

Our preparation of tyrosinase@HKUST-1 was carried out by mixing the enzyme with BTC first, homogenizing for $1 \mathrm{~min}$ and then magnetic stirring for $2 \mathrm{~h}$, followed by addition of $\mathrm{CuAc}_{2}$. Several trials have been done with results showing that direct addition of $\mathrm{CuAc}_{2}$ to the mixture of BTC + enzyme led to the production of catalysts with rather poor stability. Therefore, we figure that mixing BTC with the enzyme for $2 \mathrm{~h}$ prior to addition of $\mathrm{CuAc}_{2}$ is critical to ensure the generation of super stable enzyme@HKUST-1 biocomposites. BTC may play the role as a cross-linker to the enzyme by having its three 


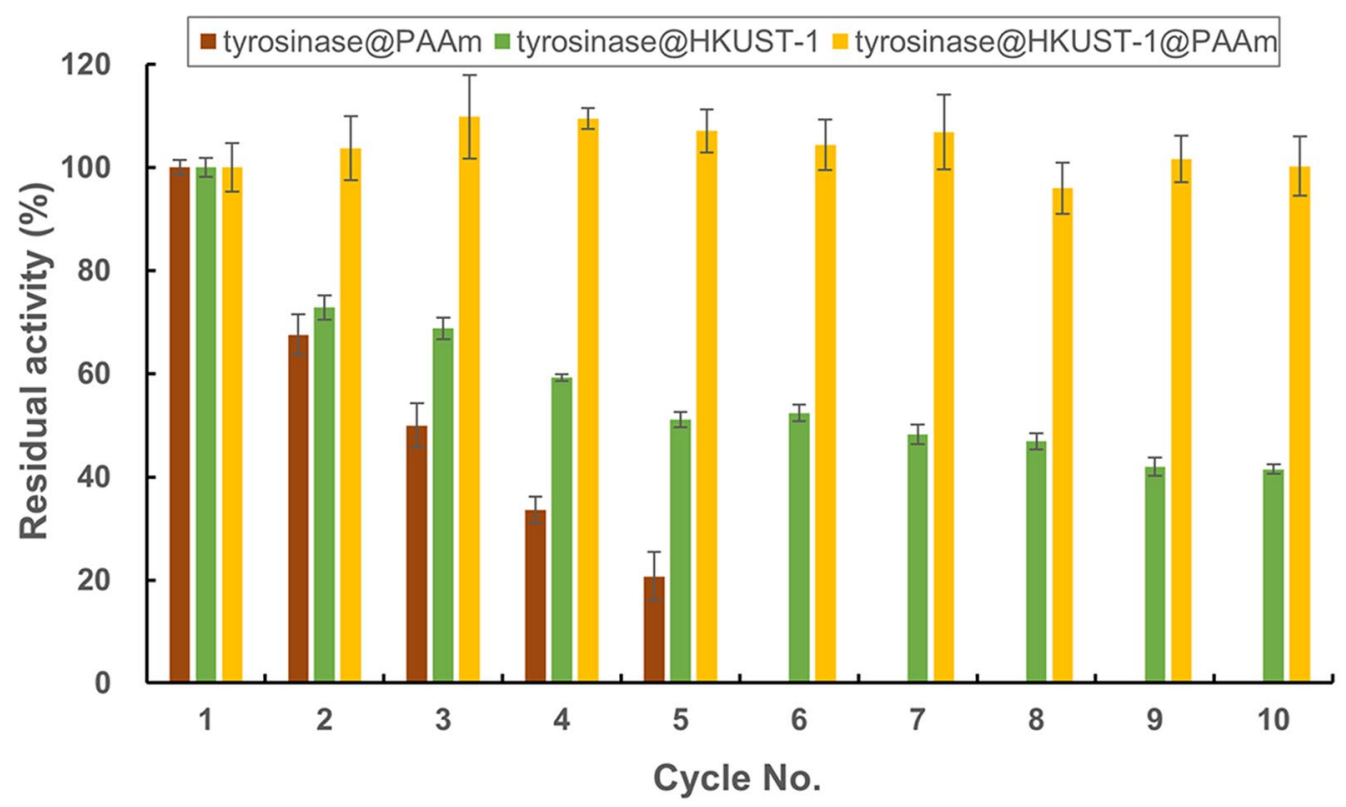

Fig. 4 Recyclability of tyrosinase@HKUST-1

carboxylic groups interacting with the enzyme through electrostatic and $\mathrm{H}$-bonding interactions. In particular, for tyrosinase with copper ions at its active site, the carboxylic groups of BTC might also have the possibility of interacting with the enzyme through coordination; however whether this is good or bad for the enzyme performance remains to be examined.

On the contrary, laccase@HKUST-1 was prepared by mixing the enzyme with $\mathrm{CuAc}_{2}$ before BTC was introduced (Zhang et al. 2020). This might be taken as a support of our assumption above, and a higher stability would be expected if the order of adding BTC and $\mathrm{CuAc}_{2}$ were reversed.

Lipase@HKUST-1, on the other hand, was prepared by adding the prior produced HKUST-1 crystal powders to the lipase solution (Nobakht et al. 2018). Therefore, the enzyme was immobilized on the support only through physical adsorption, and the enzyme molecules may be only attached on the outer surface of the HKUST-1 crystals. The weak interactions between the enzyme and the support may directly account for the poor stability of lipase@HKUST-1 reported in Nobakht et al. (2018).

It is worth mentioning that although BTC is a tricarboxylic acid and hence HKUST-1 may be acid-sensitive, our preparation of tyrosinase@HKUST-1 was actually done under acidic conditions (final $\mathrm{pH}$ of the preparation mixture was recorded to be 4.5). All the above results have shown that regardless of being subjected to this acidic treatment, the immobilized enzyme remained active and highly stable.

\section{Use of tyrosinase@HKUST-1 as catalyst for catecholic product synthesis}

In order to demonstrate its applicability, tyrosinase@ HKUST-1 was employed as catalyst for the production of two catecholic products: hydroxytyrosol (HT) and L-DOPA (Scheme 1). HT is one of the most potent natural antioxidants (Britton et al. 2019) conferring a variety of pronounced health benefits such as anti-cancer, antiinflammatory, and anti-carcinogenic properties, just to name a few, and hence has been considered an excellent food supplement by nutraceutical and food industries (Bertelli et al. 2020). L-DOPA, on the other hand, is a drug of choice for the treatment of Parkinson's disease (Nagatsu and Sawadab 2009). There has been a huge market requirement for these catecholic products, and production by means of biocatalysts appears as the optimal direction for cost-effective bio-based industrial processes (Achmon and Fishman 2014; Britton et al. 2019).

Our previous research has demonstrated that tyrosinase is capable of producing catecholic products such as L-DOPA (Xu et al. 2012; Wei et al. 2020b), 4-dihydroxyphenylacetic acid (Cheng et al. 2018), piceatannol (Cheng et al. 2018; Wei et al. 2020b), and 3'-hydroxypterostilbene (Cheng et al. 2018; Wei et al. 2020a) from their corresponding monophenol precursors. The rationale behind is the specific regioselectivity of the enzyme (Scheme 1): It catalyzes the conversion from a monophenol to an $o$-diphenol (cresolase activity) and subsequently to an $o$-quinone (catecholase activity); with the aid of a strong reductant such as L-ascorbate, the $o$-quinone can be 


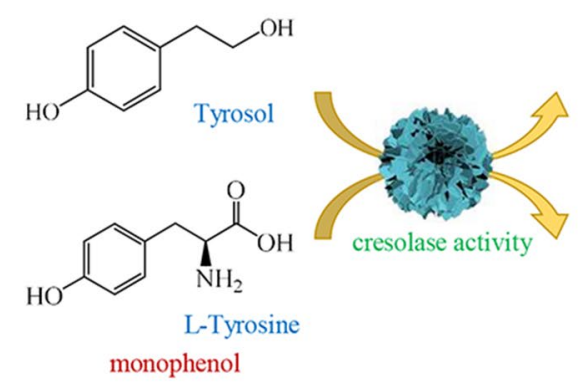

Tyrosinase@HKUST-1

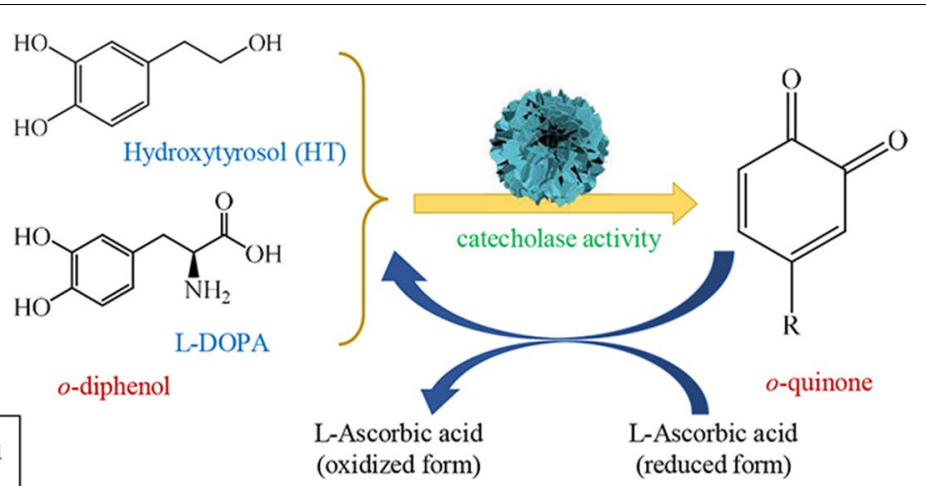

(oxidized form)

L-Ascorbic acid

$$
\text { T-1 }
$$

Scheme 1 The reaction scheme for the enzymatic synthesis of catecholic products catalyzed by tyrosinase@HKUST-1

reduced back to its $o$-diphenol form (catecholic product), leaving it as the sole product.

The successful production of HT from tyrosol through ortho-hydroxylation, catalyzed by tyrosinase@HKUST1 , was verified by HPLC (Fig. 5a) and TLC analyses (Fig. 5b). A typical time course of the synthetic reaction is presented in Fig. 5c. The product (HT) was gradually formed, concomitant with the depletion of the substrate (tyrosol), leaving the sum of the concentrations of the two to remain fairly constant (equal to the original input of the substrate). This confirms that the new biocatalyst was effective for the synthesis and that the reaction is highly selective, with HT as the only product in the presence of a sufficient supply of the reductant, L-ascorbic acid.

The effects of catalyst dosage and concentrations of the reductant and substrate on the product formation are shown in Fig. 6. The initial reaction rate increased as a higher amount of the catalyst was applied (Fig. 6a). Regarding the impact of the reductant $\mathrm{L}$-ascorbic acid (Fig. 6b), its concentration ranging between 35 to $65 \mathrm{mM}$ did not alter the production yield very much; while the rather poor yield obtained in the presence of $25 \mathrm{mM} \mathrm{L}$-ascorbic acid is simply ascribed to the fact that the $o$-diphenol product HT was further oxidized to its $o$-quinone form when the reductant ran out, which was also reflected in the progress curves of the reaction (data not shown). On the other hand, within the same reaction period the yield fell in response to an increase in the substrate concentration (Fig. 6c), which could be partially explained by the competitive inhibition to the enzyme exerted by a high concentration of $o$-diphenols (Deri-Zenaty et al. 2020). A yield as high as $94.4 \%$ was achieved in $3.5 \mathrm{~h}$ when the original tyrosol concentration was $5.0 \mathrm{mM}$.

So far there have been only 5 papers in literature regarding the use of tyrosinase as the catalyst, crude or purified, free or immobilized, for synthesizing HT from tyrosol. A comparison is given in Table 1. Espín and coworkers (Espín et al. 2001) were the first to report a successful production of HT from tyrosol with excellent yields and productivities, by using an isolated enzyme, mushroom tyrosinase, as the catalyst (entry 1 in Table 1). The highest productivity obtained by Annunziata et al. (2021) (entry 5 in Table 1) is very much attributed to their smart design of the flow protocol using a gas/liquid biphasic system. Deri-Zenaty et al. (2020) have also reported fairly high productivities (entry 4 in Table 1), as they developed a new way of reducing the $o$-quinone product back to $o$-diphenol by coupling tyrosinase with glucose dehydrogenase, which can continuously generate NADH as the reducing agent in place of $\mathrm{L}$-ascorbic acid. Comparatively speaking, our results are not bad at all, especially when considering that the catalyst we used was prepared by using crude extract from fresh mushrooms, without the need of laborious purification procedures and construction of new metabolic or enzymatic pathways by using synthetic biology tools (Achmon and Fishman 2015; Britton et al. 2019), thus being more practical and cost-effective.

Tyrosinase@HKUST-1 is also an efficient catalyst for the synthesis of L-DOPA from its monophenol precursor L-tyrosine. The product was identified by using HPLC (data not shown). Like the above reaction for HT production, increasing the catalyst dosage also led to a higher amount of the product L-DOPA to be formed (data not shown). Figure 7 shows the progress curves of the synthetic reaction in the presence of different concentrations of $\mathrm{L}$-ascorbic acid. It is general that in the presence of the reductant, L-DOPA was more and more produced along with time; but then its level would drop simply because the reduced form of L-ascorbate was increasingly converted to its oxidized form, thus leading 

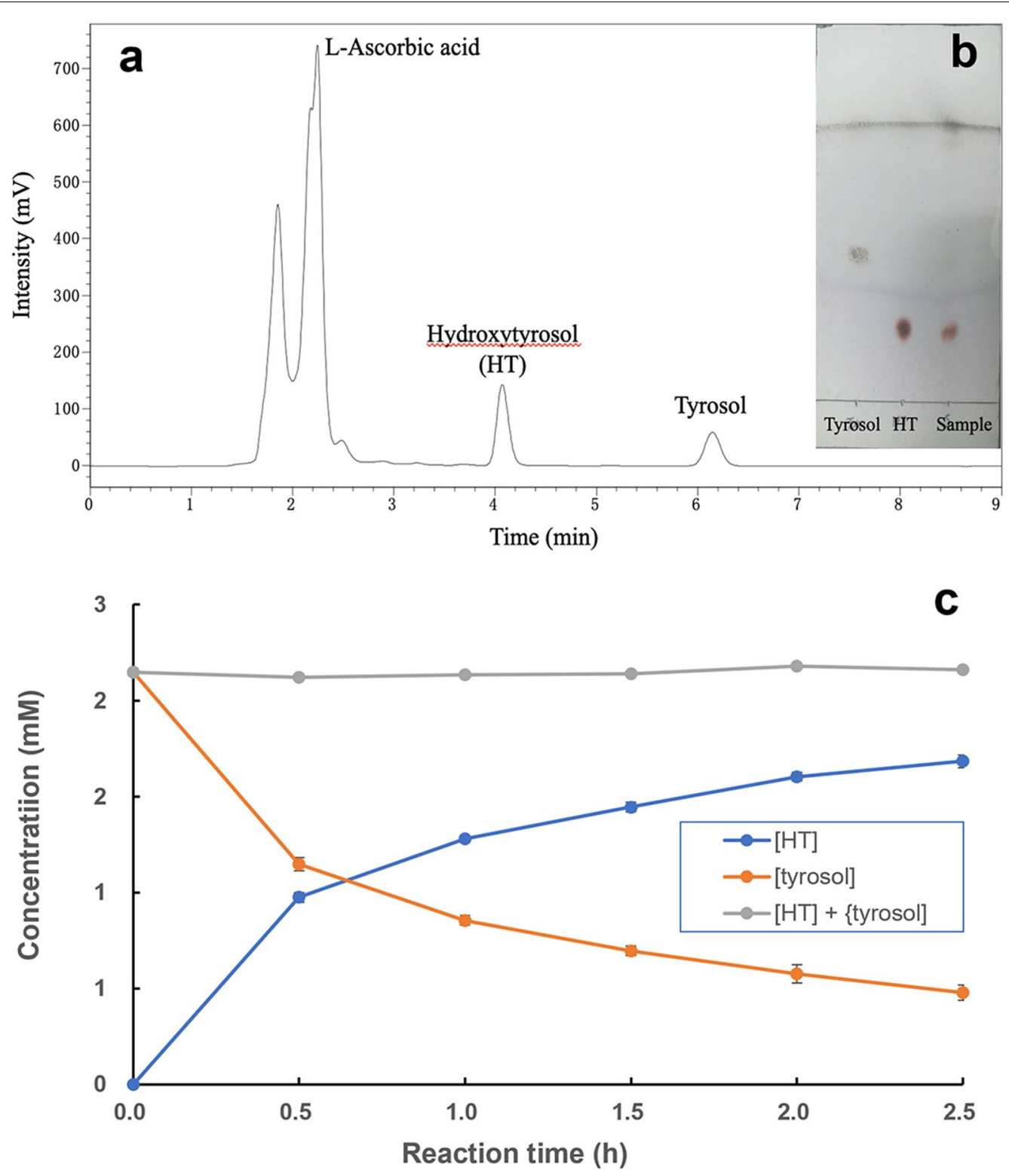

Fig. 5 Production of hydroxytyrosol (HT) from tyrosol catalyzed by tyrosinase@HKUST-1 (I): identification of the substrate and product by means of HPLC (a) and TLC (b); time courses of the synthetic reaction (c)

to the diminishing of its reducing power. A variation in the reductant concentration $(10-50 \mathrm{mM})$ did not seem to alter the initial reaction rate (see the product formed within $0-1 \mathrm{~h}$ ). But as L-ascorbate concentration became higher, it took a longer time for the reaction to reach the maximal L-DOPA concentration, accompanied by a higher yield obtained at $3.5 \mathrm{~h}$. This is understandable when taking the reducing power of $\mathrm{L}$-ascorbic acid into consideration. The same phenomenon was also observed in our recent study when TCHCs were applied to catalyze the synthesis of piceatannol from resveratrol (Wei et al. 2020b). In the presence of $30 \mathrm{mM} \mathrm{L}$-ascorbic acid 


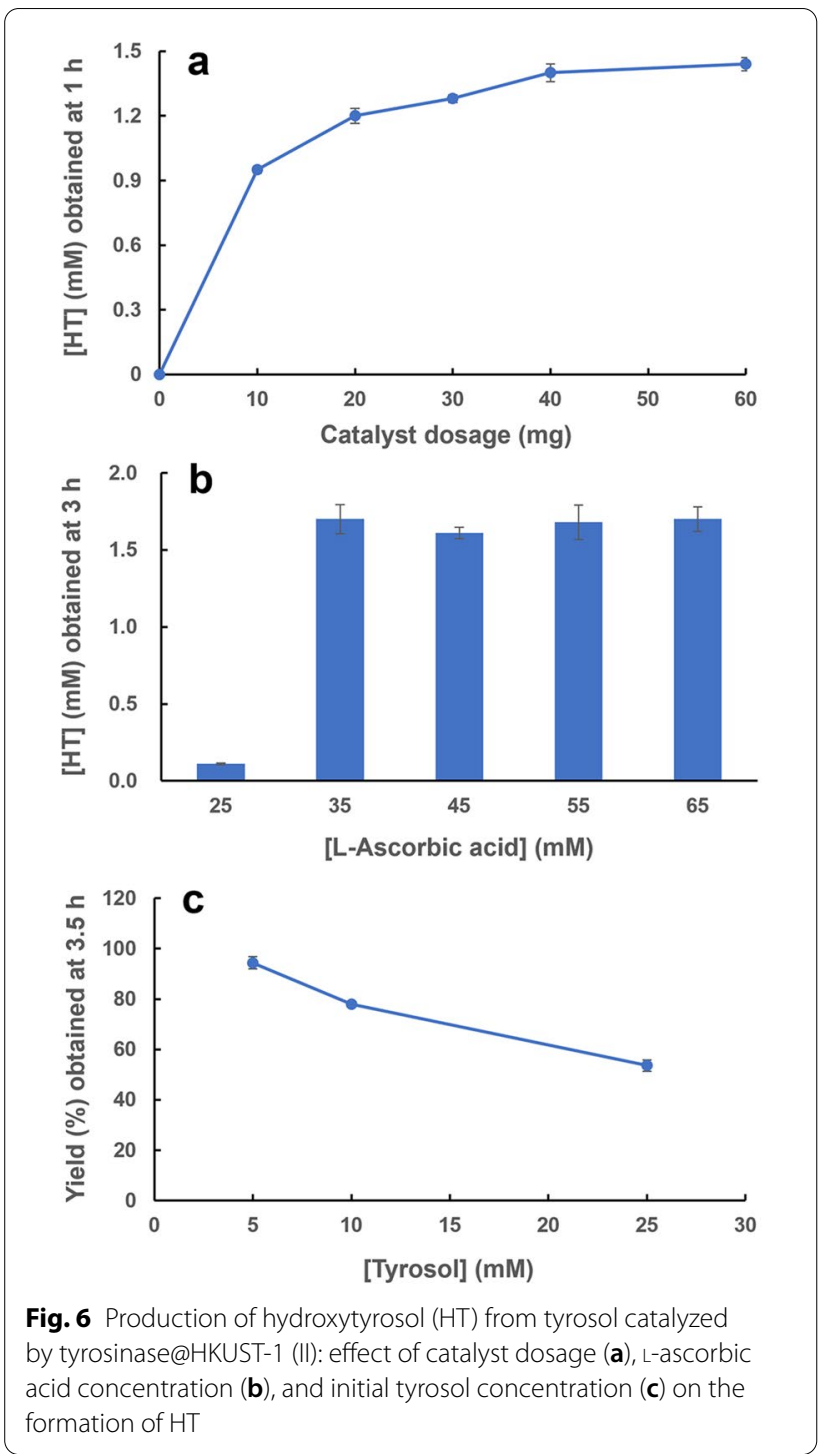

when $50 \mathrm{mg}$ of tyrosinase@HKUST-1 was applied, a yield of $45.5 \%$ was achieved within $2.0 \mathrm{~h}$.

To date, many immobilization strategies have been investigated on tyrosinase so as to be used for L-DOPA synthesis. In our previous studies, advanced techniques such as CLEAs (Xu et al. 2012), enzyme-inorganic (Wei et al. 2020b) and enzyme-MOF hybrid composites (Wei et al. 2021) have been utilized to immobilize mushroom tyrosinase for catalyzing the L-DOPA synthesis with excellent yields and productivities. Although the results obtained in this current study were not that satisfactory as compared to our previous ones, they are actually higher than most of others reported in literature (for a comparison see the Table 2 in Wei et al. (2020b)), and better results should be expected after optimization.

\section{Conclusions}

This work offers a third example of immobilizing enzymes on HKUST-1, demonstrating that the simple procedure of mixing the enzyme first with BTC followed by addition of $\mathrm{CuAc}_{2}$ is successful for the preparation of tyrosinase@HKUST-1 with super stability. The biocatalyst thus formed is highly effective to catalyze the synthesis of hydroxytyrosol and L-DOPA with great yields and productivities. In a very recent paper, Chen et al. (2021) have proposed a strategy of assembling proteins into biohybrid frameworks with the use of $\pi$-conjugated carboxylic acids as the organic linkers, and the authors have claimed that the so-formed biohybrids have highly crystalline framework structure, record-high protein contents, and ultrahigh chemical stability and bioactivity. Our work provides a good support to this. Therefore, as a new

Table 1 Production of hydroxytyrosol from tyrosol catalyzed by tyrosinase, crude or purified, free or immobilized, from different sources

\begin{tabular}{|c|c|c|c|c|c|c|c|}
\hline & Enzyme source & Catalyst form & $\begin{array}{l}\text { [tyrosol] } \\
(\mathrm{mM})\end{array}$ & Time (h) & Yield (\%) & $\begin{array}{l}\text { Productivity } \\
\text { (g/L/h) }\end{array}$ & Refs. \\
\hline 1 & Agaricus bisporus & Purified, free enzyme & 16 & 4 & 100 & 0.62 & Espín et al. (2001) \\
\hline 2 & Pycnoporus sanguineus & Purified, free enzyme & 4 & 1 & 29 & 0.18 & Halaouli et al. (2005) \\
\hline 3 & Pseudomonas putida F6 & $\begin{array}{l}\text { Crude, immobilized in Ca alginate } \\
\text { gel }\end{array}$ & 1 & 2.5 & 77 & 0.05 & Brooks et al. (2006) \\
\hline \multirow[t]{4}{*}{4} & \multirow{4}{*}{$\begin{array}{l}\text { Bacillus megaterium, expressed } \\
\text { in E. coli, coupled with glucose } \\
\text { dehydrogenase }\end{array}$} & \multirow[t]{4}{*}{ Purified, immobilized in sol-gel } & 1 & 0.5 & 100 & 0.31 & \multirow[t]{4}{*}{ Deri-Zenaty et al. (2020) } \\
\hline & & & 5 & 1.5 & 100 & 0.51 & \\
\hline & & & 10 & 2.2 & 97 & 0.68 & \\
\hline & & & 50 & 048 & 99 & 0.16 & \\
\hline 5 & Agaricus bisporus & Purified, free enzyme & 10 & 0.5 & 78 & 2.40 & Annunziata et al. (2021) \\
\hline 6 & Agaricus bisporus & $\begin{array}{l}\text { Crude, immobilized as tyrosi- } \\
\text { nase@HKUST-1 }\end{array}$ & 5 & 3.5 & 94.4 & 0.21 & This study \\
\hline
\end{tabular}




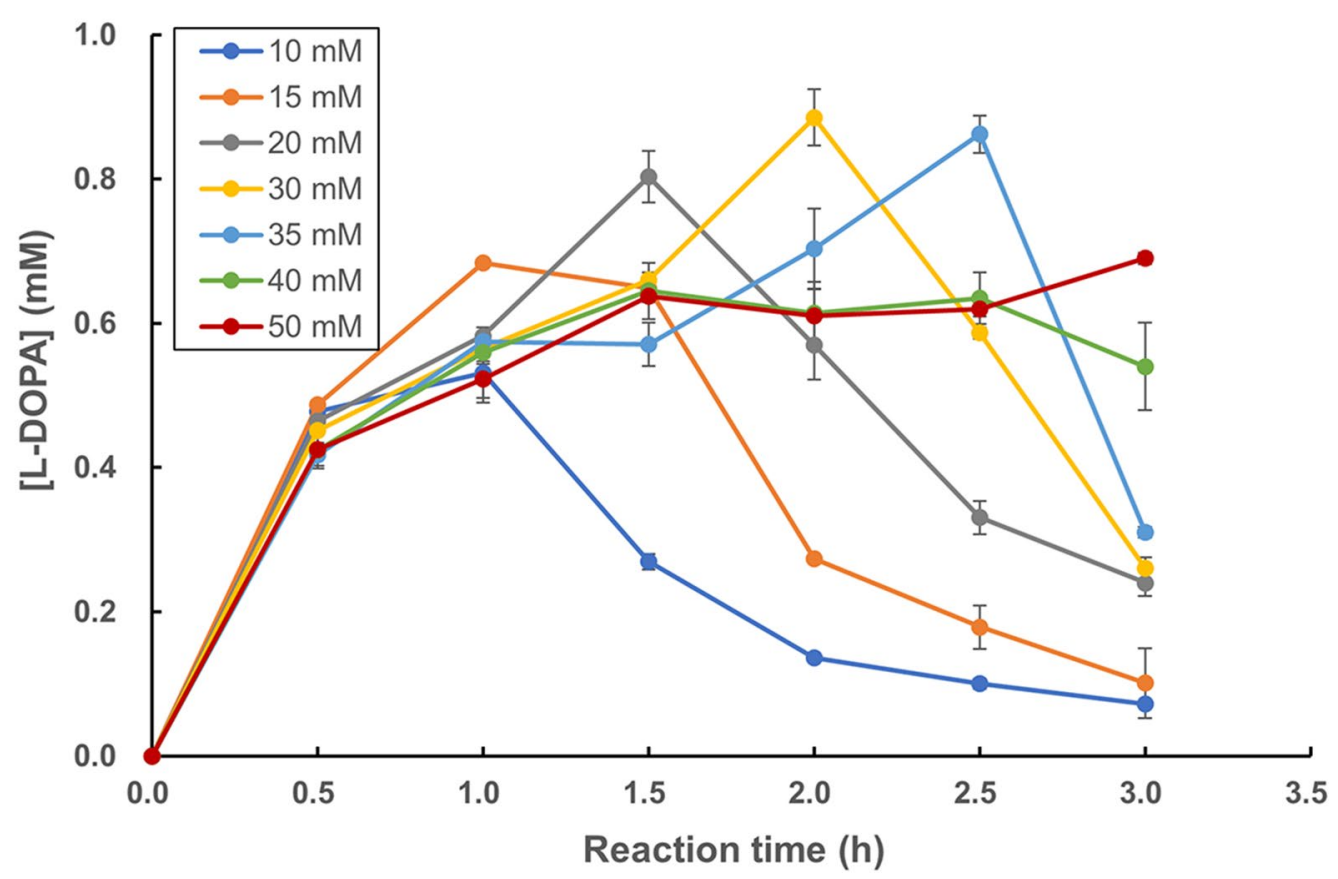

Fig. 7 Effect of L-ascorbic acid concentration on production of L-DOPA from L-tyrosine catalyzed by tyrosinase@HKUST-1

immobilization platform HKUST-1 can be introduced to other enzymes for immobilization, and the soformed tyrosinase@HKUST-1 can be applied to the production of other catecholic products with commercial importance.

\section{Abbreviations \\ MOFs: Metal-organic frameworks; BTC: Benzene 1,3,5-tricarboxylate; HKUST-1: A type of MOFs with a molecular formula of $\left[\mathrm{Cu}_{3}(\mathrm{BTC})_{2}\left(\mathrm{H}_{2} \mathrm{O}\right)_{n}\right]$; $\mathrm{CLEAs}$ : Cross- linked enzyme aggregates; TCHCs: Tyrosinase- $\mathrm{Cu}_{3}\left(\mathrm{PO}_{4}\right)_{2}$ hybrid composites; ZIFs: Zeolitic imidazolate frameworks; XRD: X-ray diffraction; FT-IR: Fourier transform infrared spectroscopy; SEM: Scanning electron microscopy; EDS: Energy-dispersive X-ray diffraction spectroscopy; HPLC: High-performance liquid chromatography; TLC: Thin-layer chromatography; L-DOPA: L-3,4-Dihy- droxyphenylalanine; $\mathrm{HT}$ : Hydroxytyrosol.}

\section{Acknowledgements}

This work was supported by Shenzhen Sustainable Development Science and Technology Project (KCXFZ20201221173404012, KCXFZ20201221173211033). We thank Ms. Wei-Qin Ao for her kind assistance in XRD analysis.

\section{Authors' contributions}

X-FL: project planning, investigation. C-YF: data curation, graphs and figures drawing. SL: funding acquisition. G-HL: investigation. ZY: project administration, supervision, paper writing. All authors read and approved the final manuscript.

\section{Funding}

Shenzhen Sustainable Development Science and Technology Project (KCXFZ20201221173404012, KCXFZ20201221173211033).

\section{Availability of data and materials}

All data generated or analyzed during this study are included in this published article, and are available from the corresponding author on reasonable request.

\section{Declarations}

Ethics approval and consent to participate

Not applicable.

\section{Consent for publication}

Not applicable.

\section{Competing interests}

The authors declare that they have no competing interests.

\section{Author details}

${ }^{1}$ College of Life Sciences and Oceanography, Shenzhen Key Laboratory of Microbial Genetic Engineering, Shenzhen University, 1066 Xue Yuan Avenue, Shenzhen 518055, Guangdong, China. ${ }^{2}$ College of Life Sciences and Oceanography, Shenzhen Key Laboratory of Marine Bioresources and Eco-Environmental Science, Shenzhen University, Shenzhen 518055 Guangdong, China.

Received: 21 Auqust 2021 Accepted: 18 October 2021

Published online: 27 October 2021

\section{References}

Achmon Y, Fishman A (2015) The antioxidant hydroxytyrosol: biotechnological production challenges and opportunities. Appl Microbiol Biotechnol 99:1119-1130. https://doi.org/10.1007/s00253-014-6310-6

Al-Janabi N, Hill P, Torrente-Murciano L, Garforth A, Gorgojo P, Siperstein F, Fan X (2015) Mapping the Cu-BTC metal-organic framework (HKUST-1) stability envelope in the presence of water vapour for $\mathrm{CO}_{2}$ adsorption from flue gases. Chem Eng J 281:669-677. https://doi.org/10.1016/j.cej. 2015.07.020

Annunziata F, Contente ML, Pinna C, Tamborini L, Pinto A (2021) Biocatalyzed flow oxidation of tyrosol to hydroxytyrosol and efficient production of their acetate esters. Antioxidants 10:1142. https://doi.org/10.3390/antio $\times 10071142$ 
Atlow SC, Bonadonna-Aparo L, Klibanov AM (1984) Dephenolization of industrial wastewaters catalyzed by polyphenol oxidase. Biotechnol Bioeng 26:599-603

Bertelli M, Kiani AK, Paolacci S, Manara E, Kurti D, Dhuli K, Bushati V, Miertus J, Pangallo D, Baglivo M, Beccari T, Michelini S (2020) Hydroxytyrosol: a natural compound with promising pharmacological activities. J Biotechnol 309:29-33. https://doi.org/10.1016/j.jbiotec.2019.12.016

Britton J, Davis R, O'Connor KE (2019) Chemical, physical and biotechnological approaches to the production of the potent antioxidant hydroxytyrosol. Appl Microbiol Biotechnol 103:5957-5974. https://doi.org/10.1007/ s00253-019-09914-9

Brooks SJ, Doyle EM, O'Connor KE (2006) Tyrosol to hydroxytyrosol biotransformation by immobilised cell extracts of Pseudomonas putida F6. Enzyme Microb Technol 39:191-196. https://doi.org/10.1016/j.enzmictec.2005. 10.025

Chen G, Huang S, Shen Y, Kou X, Ma X, Zhu F, Huang S, Tong Q, Ma K, Chen W, Wang P, Shen J, Ouyang G (2021) Protein-directed, hydrogen-bonded biohybrid framework. Chem 7:1-21. https://doi.org/10.1016/j.chempr. 2021.07.003

Cheng H, Zou Y, Luo X, Song XH, Yang Z (2018) Enzymatic synthesis of catechol-functionalized polyphenols with excellent selectivity and productivity. Process Biochem 70:90-97. https://doi.org/10.1016/j.procb io.2018.03.028

Chui SS-Y, Lo SM-F, Charmant JPH, Orpen AG, Williams ID (1999) A chemically functionalizable nanoporous material. Science 283(5405):1148-1150

Deri-Zenaty B, Bachar S, Rebroš M, Fishman A (2020) A coupled enzymatic reaction of tyrosinase and glucose dehydrogenase for the production of hydroxytyrosol. Appl Microbiol Biotechnol 104:4945-4955. https://doi. org/10.1007/s00253-020-10594-z

Espín JC, Soler-Rivas C, Cantos E, Tomás-Barberán FA, Wichers HJ (2001) Synthesis of the antioxidant hydroxytyrosol using tyrosinase as biocatalyst. J Agric Food Chem 49:1187-1193

Halaouli S, Mi A, Kruus K, Guo L, Hamdi M, Sigoillot J-C, Asther M, Lomascolo A (2005) Characterization of a new tyrosinase from Pycnoporus species with high potential for food technological applications. J Appl Microbiol 98:332-343. https://doi.org/10.1111/j.1365-2672.2004.02481.x

Huo J, Brightwell M, Hankari SE, Garai A, Bradshaw D (2013) A versatile, industrially relevant, aqueous room temperature synthesis of HKUST-1 with high space-time yield. J Mater Chem a 1:15220-15223. https://doi.org/10 1039/c3ta14409g

Lian X, Huang Y, Zhu Y, Fang Y, Zhao R, Joseph E, Li J, Pellois JP, Zhou HC (2018) Enzyme-MOF nanoreactor activates nontoxic paracetamol for cancer therapy. Angew Chem Int Ed 57:5725-5730. https://doi.org/10.1002/ ange.201801378

Liang S, Wu XL, Xiong J, Zong MH, Lou WY (2020) Metal-organic frameworks as novel matrices for efficient enzyme immobilization: An update review. Coordination Chem Rev 406:213149. https://doi.org/10.1016/j.ccr.2019. 213149

Lu X, Wang X, Wu L, Wu L, Dhanjai FuL, Gao Y, Chen J (2016) Response characteristics of bisphenols on a metal-organic framework-based tyrosinase nanosensor. ACS Appl Mater Interfaces 8:16533-16539. https://doi.org/ 10.1021/acsami.6b05008

Nagatsu T, Sawadab M (2009) L-dopa therapy for Parkinson's disease: past, present, and future. Parkinsonism Relat Disord 15(Suppl. 1):S3-S8. https:// doi.org/10.1016/S1353-8020(09)70004-5

Nobakht N, Faramarzi MA, Shafiee A, Khoobi M, Rafiee E (2018) Polyoxometalate-metal organic framework-lipase: an efficient green catalyst for synthesis of benzyl cinnamate by enzymatic esterification of cinnamic acid. Int J Biol Macrom 113:8-19. https://doi.org/10.1016/j.ijbiomac.2018. 02.023
Nistor C, Emnéus J, Gorton L, Ciucu A (1999) Improved stability and altered selectivity of tyrosinase based graphite electrodes for detection of phenolic compounds. Anal Chim Acta 387:309-326

Pialis P, Saville BA (1998) Production of L-DOPA from tyrosinase immobilized on nylon 6,6: enzyme stability and scaleup. Enzyme Microb Technol 22:261-268

Robb DA (1984) Tyrosinase. In: Lontie R (ed) Copper proteins and copper enzymes, vol. II, CRC Press, Boca Raton, pp. 207-241.

Vaidya LB, Nadar SS, Rathod VK (2020) Metal-organic frameworks (MOFs) for enzyme immobilization. In: Mozafari M (ed) Metal-organic frameworks for biomedical applications. Elsevier, pp. 491-523. https://doi.org/10.1016/ b978-0-12-816984-1.00024-X.

Wang X, Lu X, Wu L, Chen J (2015) 3D metal-organic framework as highly efficient biosensing platform for ultrasensitive and rapid detection of bisphenol A. Biosensors Bioelectron 65:295-301. https://doi.org/10. 1016/j.bios.2014.10.010

Wei Y-X, Lü X-F, Cheng H, Luo J-Y, Zou Y, Yang Z (2020a) Enzymatic synthesis of a catecholic polyphenol product with excellent antioxidant activity. Biocatal Biotransf 38:431-437. https://doi.org/10.1080/10242422.2020. 1756789

Wei Y-X, Wei C-M, Li S, Zou Y, Yang Z (2020b) Novel biocatalyst for efficient synthesis of catecholic products. ACS Sustain Chem Eng 8:12277-12285. https://doi.org/10.1021/acssuschemeng.0c04186

Wei C-M, Feng C-Y, Li S, Zou Y, Yang Z (2021) Mushroom tyrosinase immobilized on metal-organic frameworks as an excellent catalyst for both catecholic product synthesis and phenolic wastewater treatment. J Biotechnol. (submitted).

Xu D-Y, Yang Z (2013) Cross-linked tyrosinase aggregates for elimination of phenolic compounds from wastewater. Chemosphere 92:391-398. https://doi.org/10.1016/j.chemosphere.2012.12.076

Xu D-Y, Yang Y, Yang Z (2011) Activity and stability of cross-linked tyrosinase aggregates in aqueous and nonaqueous media. J Biotechnol 152:30-36. https://doi.org/10.1016/j.jbiotec.2011.01.014

Xu D-Y, Chen J-Y, Yang Z (2012) Use of cross-linked tyrosinase aggregates as catalyst for synthesis of L-DOPA. Biochem Eng J 63:88-94. https://doi.org/ 10.1016/j.bej.2011.11.009

Yang Z, Robb DA (1993) Comparison of tyrosinase activity and stability in aqueous and nearly nonaqueous environments. Enzyme Microb Technol 15:1030-1036. https://doi.org/10.1016/0141-0229(93)90050-C

Yuan S, Feng L, Wang K, Pang J, Bosch M, Lollar C, Sun Y, Qin J, Yang X, Zhang P, Wang Q, Zou L, Zhang Y, Zhang L, Fang Y, Li J, Zhou HC (2018) Stable metal-organic frameworks: design, synthesis, and applications. Adv Mater 30:e1704303. https://doi.org/10.1002/adma.201704303

Zhang R, Wang L, Han J, Wu J, Li C, Ni L, Wang Y (2020) Improving laccase activity and stability by HKUST-1 with cofactor via one-pot encapsulation and its application for degradation of bisphenol A. J Hazardous Mater 383:121130. https://doi.org/10.1016/j.jhazmat.2019.121130

\section{Publisher's Note}

Springer Nature remains neutral with regard to jurisdictional claims in published maps and institutional affiliations.

\section{Submit your manuscript to a SpringerOpen ${ }^{\circ}$ journal and benefit from:}

- Convenient online submission

- Rigorous peer review

- Open access: articles freely available online

- High visibility within the field

- Retaining the copyright to your article

Submit your next manuscript at springeropen.com 